\title{
The International Metallographic Society Presents Microstructural Characterization at IMAT 2020
}

\author{
Donald F. Susan ${ }^{1} \cdot$ Daniel P. Dennies ${ }^{2}$
}

(c) ASM International 2019

The International Metallographic Society (IMS) will play a key role at IMAT 2020, a new multi-disciplinary materials and applications conference organized by ASM and its partners. IMS plans to have a significant presence at IMAT 2020 and looks forward to collaborating with the other Affiliate Societies of ASM, as well as other materials groups from across the country, to bring a high level of technical programming to this new conference and make it the go-to technical gathering of materials professionals in the future.

The disciplines of metallography and microstructural characterization cut across all material types and all industries. Understanding microstructure and the relationship between microstructure and properties helps drive the cutting edge of industry, including lightweight technologies, smart materials, and additive manufacturing. It also supports investigative research in wide ranging fields such as archaeometallurgy, ceramics/glasses, microelectronics, and alloy development including high-entropy alloys. Metallography and metallographic interpretation is used in the full spectrum of materials science, from quality control at steel mills to advanced sample preparation for electron backscatter diffraction (EBSD) in high-end research laboratories.

In order to cover this all-encompassing field, a wide range of symposia and short course topics will be covered at IMAT 2020 including

(1) Correlation of Microstructure to Mechanical Properties

(2) Metallographic Preparation Techniques

(3) Quantification and Simulation of Microstructures and Properties

Donald F. Susan

dfsusan@sandia.gov

1 Sandia National Labs, PO Box 5800, Albuquerque, NM 87185-0100, USA

2 DMS Inc., 26741 Portola Parkway, Suite 1E-707, Foothill Ranch, CA 92610, USA

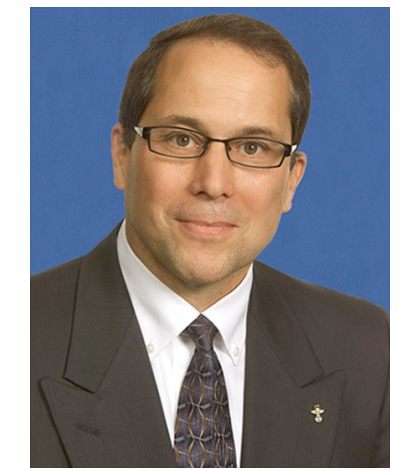

Daniel P. Dennies, IMS President

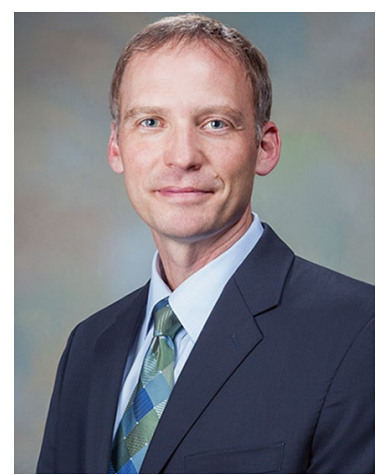

Don Susan, IMS IMAT 2020 Chair

Selected papers may be considered for a future issue of Metallography, Microstructure, and Analysis.

An important part of the IMS calendar at IMAT 2020 will be the International Metallographic Contest (IMC), a vehicle for metallographers and researchers to display their skills and compete for the prestigious grand prize Jacquet-Lucas Award. In addition, each year IMS recognizes an outstanding person with the Sorby Award for lifetime contributions to the field of metallography.

We look forward to both excellent technical programming and opportunities for social and career networking at the new IMAT 2020 conference. See you in Cleveland! 